\title{
Creation of an iOS and Android Mobile Application for Inferior Vena Cava (IVC) Filters: A Powerful Tool to Optimize Care of Patients with IVC Filters
}

\author{
Steven E. Deso, MD ${ }^{1} \quad$ Ibrahim A. Idakoji, MD, MPH ${ }^{1} \quad$ Michael C. Muelly, MD ${ }^{1} \quad$ William T. Kuo, MD ${ }^{1}$ \\ ${ }^{1}$ Division of Vascular and Interventional Radiology, Stanford University \\ Medical Center, Stanford, California \\ Address for correspondence Steven E. Deso, MD, Division of Vascular \\ and Interventional Radiology, Stanford University Medical Center, 300 \\ Pasteur Drive, H-3651, Stanford, CA 94305 \\ Semin Intervent Radiol 2016;33:137-143 \\ (e-mail: sdeso@stanford.edu).
}

\begin{abstract}
Owing to a myriad of inferior vena cava (IVC) filter types and their potential complications, rapid and correct identification may be challenging when encountered on routine imaging. The authors aimed to develop an interactive mobile application that allows recognition of all IVC filters and related complications, to optimize the care of patients with indwelling IVC filters. The FDA Premarket Notification Database was queried from 1980 to 2014 to identify all IVC filter types in the United States. An electronic search was then performed on MEDLINE and the FDA MAUDE database to identify all reported complications associated with each device. High-resolution photos were taken of each filter type and corresponding computed tomographic and fluoroscopic images were obtained from an institutional review board-approved IVC filter registry. A wireframe and storyboard were created, and software was developed using HTML5/CSS compliant code. The software was deployed using PhoneGap (Adobe, San Jose, CA), and the prototype was tested and refined. Twenty-three IVC filter types were identified for inclusion. Safety data from FDA MAUDE and 72 relevant peer-reviewed studies were acquired, and complication rates for each filter type were highlighted in the application. Digital photos, fluoroscopic images, and CT DICOM files were seam-

Keywords

- mobile application

- electronic tool

- interventional radiology lessly incorporated. All data were succinctly organized electronically, and the software was successfully deployed into Android (Google, Mountain View, CA) and iOS (Apple, Cupertino, CA) platforms. A powerful electronic mobile application was successfully created to allow rapid identification of all IVC filter types and related complications. This application may be used to optimize the care of patients with IVC filters.
\end{abstract}

Objectives: Upon completion of this article, the reader will be able to discuss how mobile applications are impacting today's health-care system and how they can be used to improve the care of patients with indwelling IVC filters.

Accreditation: This activity has been planned and implemented in accordance with the Essential Areas and Policies of the Accreditation Council for Continuing Medical Education (ACCME) through the joint providership of Tufts University School of Medicine (TUSM) and Thieme Medical Publishers, New York. TUSM is accredited by the ACCME to provide continuing medical education for physicians.

Issue Theme Inferior Vena Cava Filters; Guest Editors, Kush R. Desai, MD and Robert J. Lewandowski, MD
Credit: Tufts University School of Medicine designates this journal-based CME activity for a maximum of 1 AMA PRA Category 1 Credit $^{\mathrm{TM}}$. Physicians should claim only the credit commensurate with the extent of their participation in the activity.

A mobile application (app) is a computer program designed to run on electronic mobile devices such as smartphones and tablet computers. Mobile apps were originally developed for the general public to help boost productivity and information retrieval, but apps are now specifically

Copyright $\odot 2016$ by Thieme Medical Publishers, Inc., 333 Seventh Avenue, New York, NY 10001, USA. Tel: +1(212) 584-4662. 


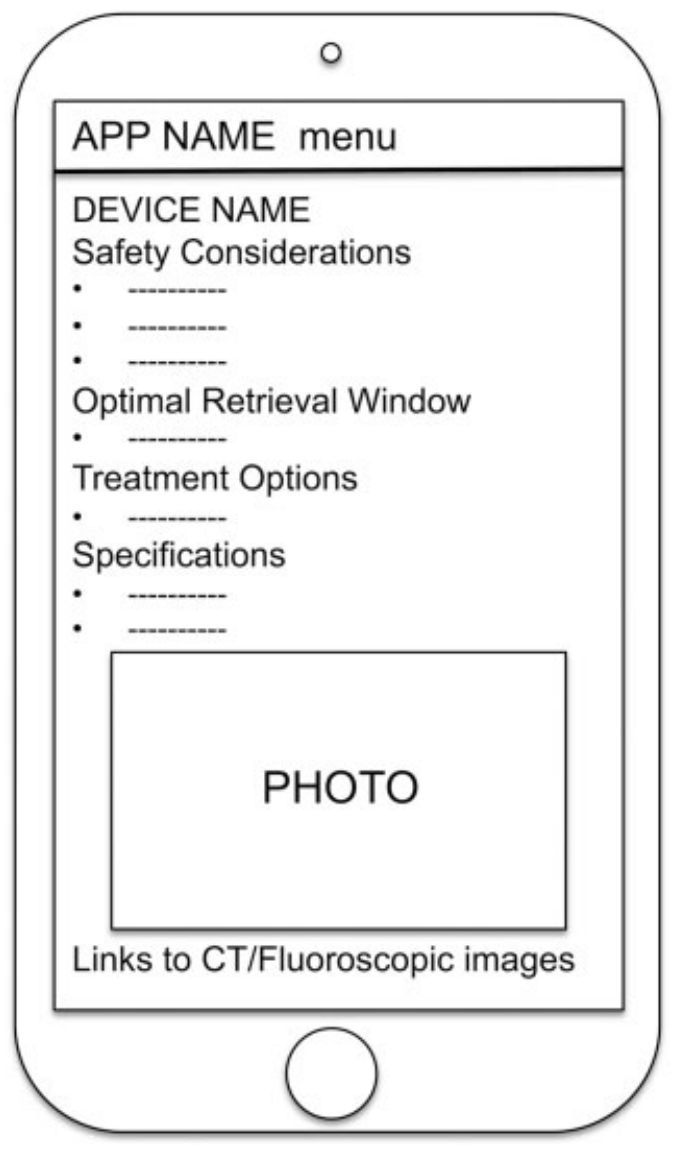

Fig. 1 Sample of initial wireframe for mobile app.

designed for a variety of fields including medicine. Apps may now assist health-care providers with a multitude of tasks including clinical references, medical calculations, and even clinical decision making. The authors aimed to apply mobile app technology to help clinicians caring for patients with indwelling inferior vena cava (IVC) filters.

In the United States, the use of IVC filters has steadily increased over the past 30 years, ${ }^{1}$ and more than 250,000 filters are now placed annually in the United States resulting in an epidemic of filter-related complications. ${ }^{2}$ Currently, the myriad of IVC filter types encountered in clinical practice, the clinical implications from prolonged implantation, and the potential for device-specific complications remain a source of confusion among clinicians. Indeed, despite the wide availability and use of cross-sectional imaging, rapid and correct identification of IVC filter types may be challenging due to the myriad of IVC filter types. The authors aimed to develop an interactive mobile app that allows recognition of all IVC filters and electronically organizes key clinical and safety data for each filter type, to provide a useful clinical tool for physicians caring for IVC filter patients.

\section{Materials and Methods}

The Food and Drug Administration (FDA) device approvals, denials, and clearances database was queried electronically for IVC filters receiving premarket (510K) approval (product code DTK-filter, intravascular, cardiovascular). ${ }^{3}$ From a pristine filter collection, high-resolution photos were taken of each filter type. A searchable institutional review boardapproved IVC filter registry (NCT01158482) was used to collect representative computed tomographic (CT) and fluoroscopic images for each device. Next, an evidence-based electronic search (MEDLINE, FDA MAUDE database) was performed to identify the key clinical and safety data for each filter type including the following: device-specific complications, optimal retrieval window, treatment options for removal, and technical specifications. ${ }^{4} \mathrm{~A}$ wireframe (-Fig. 1)

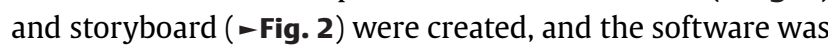
developed using HTML5/CSS compliant code and Coda2 (Panic, Portland, OR) environment. The software was then deployed using PhoneGap (Adobe), and the app prototype was tested, refined, and finalized for public launch.

\section{Results}

Twenty-four IVC filter types were identified, and 23 types were included. The Edwards Mobin-Uddin device was excluded, as it was removed from the market in $1986 .{ }^{5}$ Among FDA-approved devices, 9 were approved for permanent use and 14 were approved as retrievable and permanent devices ( $\mathbf{- T a b l e ~} \mathbf{1}$ ). The following device specifications were recorded: shape, material, delivery size, maximum IVC diameter, and magnetic resonance imaging (MRI) compatibility. The following complication rates were obtained: fracture, insertional issues, migration, perforation, recurrent venous thromboembolism, and IVC occlusion. A mobile app was constructed, using the HTML5 standard, to organize the digital photographic, radiographic, and clinical data in a format that allows easy search and instant access ( - Fig. 3). The main menu of the application (-Fig. 4) was organized into submenus for general information about IVC filters ("General"), device-specific information sheets organized alphabetically by device name ("IVC filters"), an image gallery for visual identification of IVC filters ("by Image"), literature references ("References"), and information about the application ("About").

General clinical information (-Fig. 5) was provided including the following: the 2010 and 2014 FDA safety communications regarding retrievable IVC filters ${ }^{2,6,7}$; indications for IVC filter placement based on guidelines from the Society of Interventional Radiology (SIR), American College of Chest Physicians (ACCP), American Heart Association (AHA), and Eastern Association for the Surgery of Trauma (EAST) guidelines ${ }^{8-11}$; and radiographic examples of each type of filter complication.

Devices were organized alphabetically by name in the "IVC filters" section (-Fig. 6) and linked to information pages for each of the 23 FDA-approved IVC filters. For each device page, safety considerations for each filter type, information on the optimal retrieval window, options for IVC filter removal, and representative imaging were included ( - Fig. 7). Additional specifications were placed in the "Technical Specifications" section including the FDA approval date, material, insertion routes, sheath size, maximum IVC diameter, and MRI compatibility. Representative imaging results including digital 


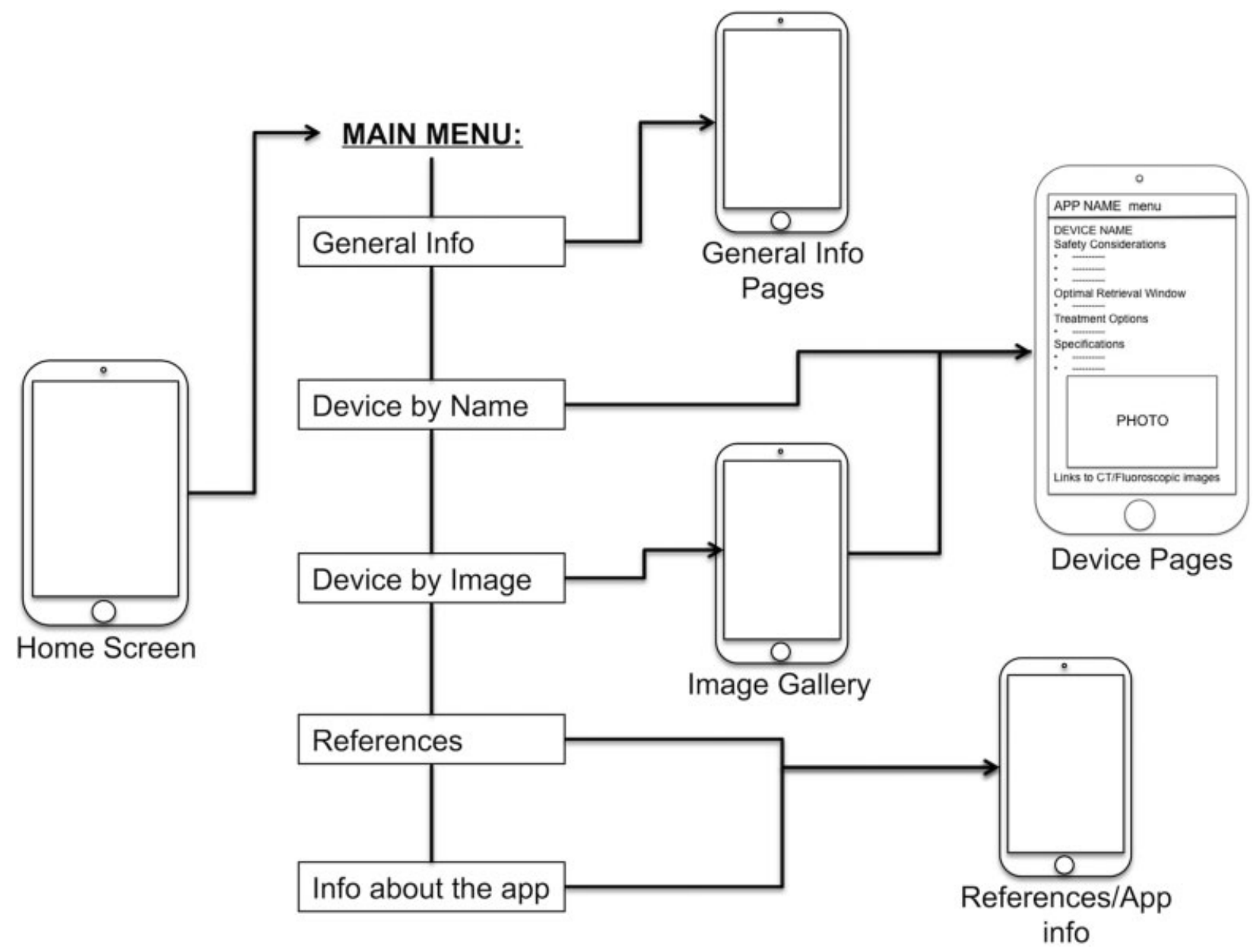

Fig. 2 Storyboard used in mobile app development.

photos and radiographs, to aid in device identification, were placed immediately beneath the "Technical Specifications" section (-Fig. 8). Fluoroscopic and interactive CT imaging studies were made available on the app (-Fig. 9). An integrated PACs system was included to allow the user to scroll through representative $\mathrm{CT}$ images for each device. In addition, an image gallery containing all 23 FDA-approved devices was made accessible from the main menu (-Fig. 10). Finally, each image from the gallery was linked to the corresponding device page for rapid access.

\section{Discussion}

Smartphones, personal digital assistants, and tablet computers have become ubiquitous in modern society. Apps are now available to assist health-care providers with various tasks including health record maintenance and access, communications, consulting, information gathering, patient management and monitoring, clinical decision making, and medical education. ${ }^{12}$ The availability of mobile devices and mobile apps has shifted the medical paradigm and given health-care providers and patients rapid access to vast amounts of information at the point of care. ${ }^{12}$ Previous studies have demonstrated that access to these point of care decision-making tools can improve clinical decisions and patient outcomes. ${ }^{13}$ Therefore, the use of mobile apps in the health-care setting can provide convenience, better clinical decision making, improved accuracy, increased efficiency, and enhanced productivity. ${ }^{12}$

Given these potential benefits, the authors aimed to develop a mobile app to help physicians who may encounter patients with potential risks or complications from indwelling IVC filters. In the United States, rising filter use has resulted in an epidemic of filter-related complications. These risks led the FDA to issue a safety alert in August 2010 recommending the removal of retrievable IVC filters as soon as protection from pulmonary embolism (PE) is no longer needed ${ }^{2}$ to prevent filter-related complications. In 2014, the FDA released another safety communication stating that the risk-to-benefit ratio begins to favor IVC filter removal within 29 to 54 days after implantation if the risk for PE has passed. ${ }^{6,7}$ Despite these warnings, an increasing number of filters and filter types are being implanted annually resulting in confusion when encountered by clinicians.

As described here, mobile IVC filter app was successfully developed allowing clinicians to identify any filter currently encountered in the United States. Once identified, the application provides a quick reference of clinically relevant data. For instance, if a Bard Recovery filter (Bard Recovery, Tempe, $\mathrm{AZ}$ ) is identified, the clinician can quickly learn that the device 
Table 1 FDA-approved IVC filters from 1980 to 2014

\begin{tabular}{|c|c|c|c|}
\hline Device & Company & FDA approved & Retrievability \\
\hline ALN & ALN International, Miami, FL & 2008 & Permanent \\
\hline Recovery & Bard Peripheral Vascular, Tempe, AZ & $2003-2005$ & Retrievable \\
\hline G2 & Bard Peripheral Vascular & $2005-2008$ & Retrievable \\
\hline G2X & Bard Peripheral Vascular & 2008 & Retrievable \\
\hline Eclipse & Bard Peripheral Vascular & 2008 & Retrievable \\
\hline Meridian & Bard Peripheral Vascular & 2011 & Retrievable \\
\hline Denali & Bard Peripheral Vascular & 2013 & Retrievable \\
\hline Simon Nitinol & Bard Peripheral Vascular & 1990 & Permanent \\
\hline LGM/Vena Tech LGM & B. Braun Medical, Bethlehem, PA & 1989 & Permanent \\
\hline Vena Tech LP & B. Braun Medical & 2001 & Permanent \\
\hline 24Fr SS Greenfield & Boston Scientific, Natick, MA & 1973 & Permanent \\
\hline 12Fr SS Greenfield & Boston Scientific & 1995 & Permanent \\
\hline Titanium Greenfield & Boston Scientific & 1989 & Permanent \\
\hline Günther Tulip & Cook, Bloomington, IN & $2000 / 03$ & Retrievable \\
\hline Celect & Cook & $2007 / 08$ & Retrievable \\
\hline Celect Platinum & Cook & 2012 & Retrievable \\
\hline Bird's Nest & Cook & 1989 & Permanent \\
\hline Optease & Cordis Endovascular, Warren, NJ & $2002 / 04$ & Retrievable \\
\hline Trapease & Cordis Endovascular & 2000 & Permanent \\
\hline Option & Argon Medical Devices, Plano, TX & 2009 & Retrievable \\
\hline Option Elite & Argon Medical Devices & 2014 & Retrievable \\
\hline Crux & Volcano, San Diego, CA & 2012 & Retrievable \\
\hline SafeFlo & Rafael Medical Technologies, Dover, DE & 2009 & Permanent \\
\hline
\end{tabular}

Abbreviations: FDA, Food and Drug Administration; IVC, inferior vena cava.

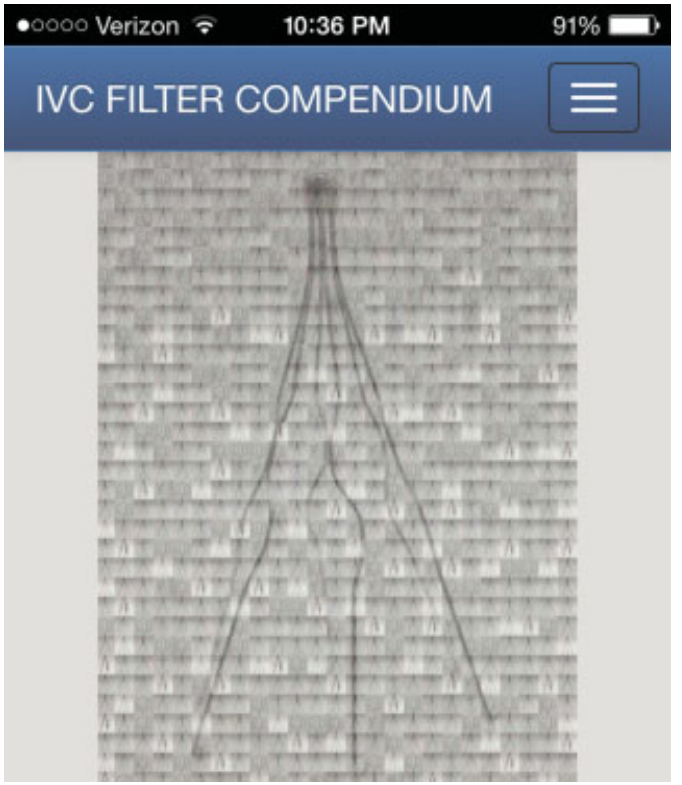

Fig. 3 Screenshot of the main page of the mobile application entitled "IVC Filter Compendium."

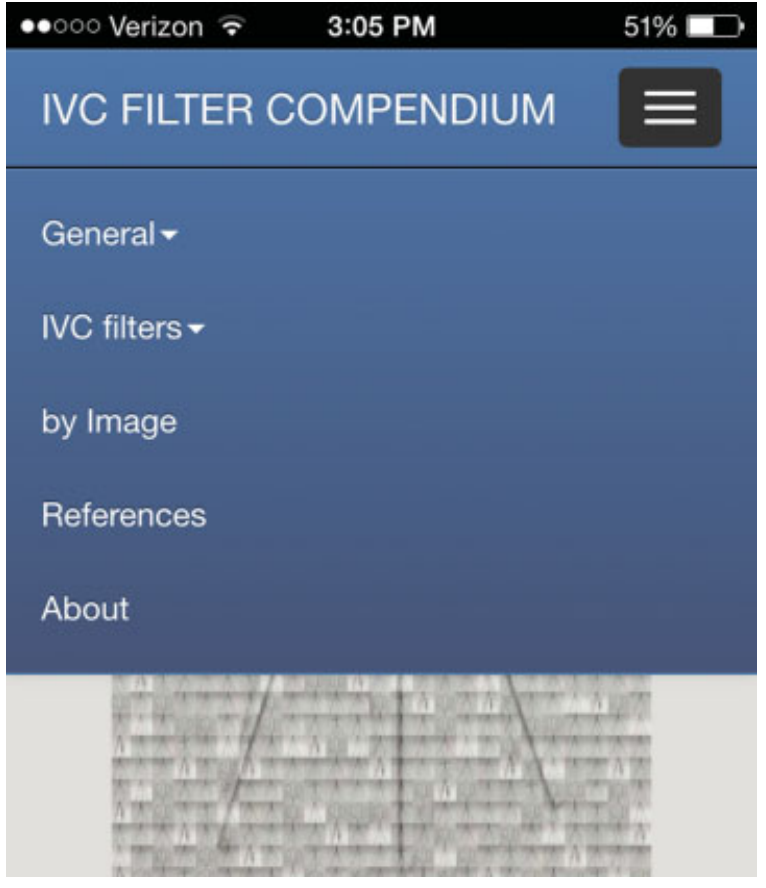

Fig. 4 Screenshot of the main drop-down menu. 


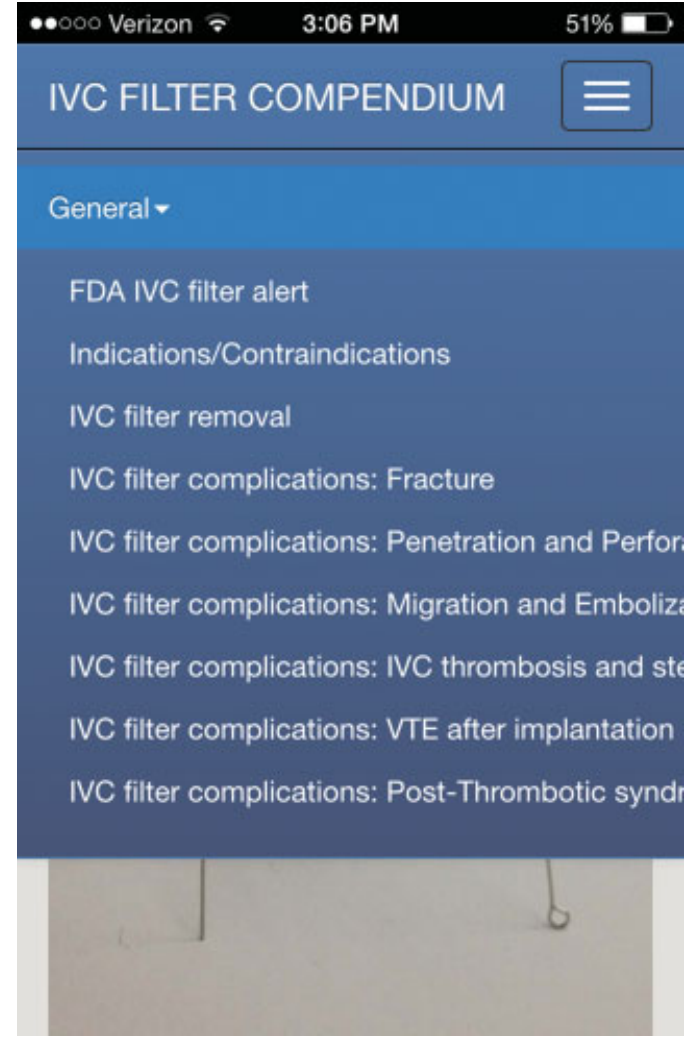

Fig. 5 Screenshot of the general information menu.

was originally FDA approved in 2003 but discontinued in 2005 due to complications (such as fracture rates up to 25\%). ${ }^{14-17}$ This knowledge may lead the clinician and/or radiologist to search for fractured and embolized filter com-

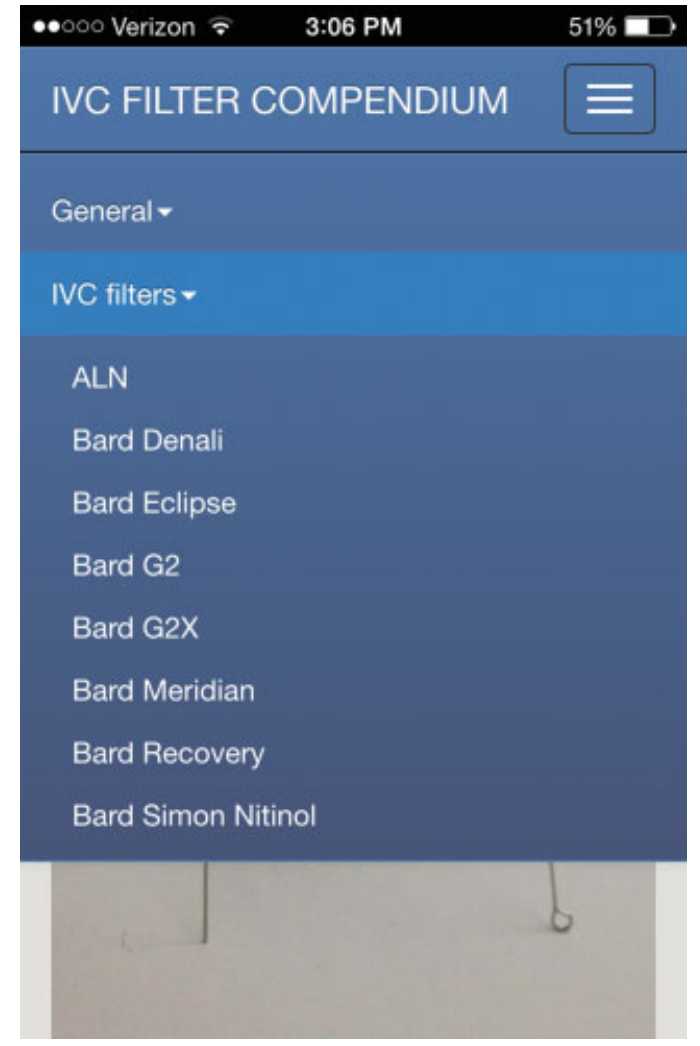

Fig. 6 Screenshot of the IVC filters menu. Additional devices may be reviewed by scrolling down the menu.

ponents more closely on radiographic studies, which may lead to recommendations for treatment with prompt filter removal. Similarly, if a Cook Celect filter (Cook Celect, Bloomington, IN) is identified in a patient presenting with

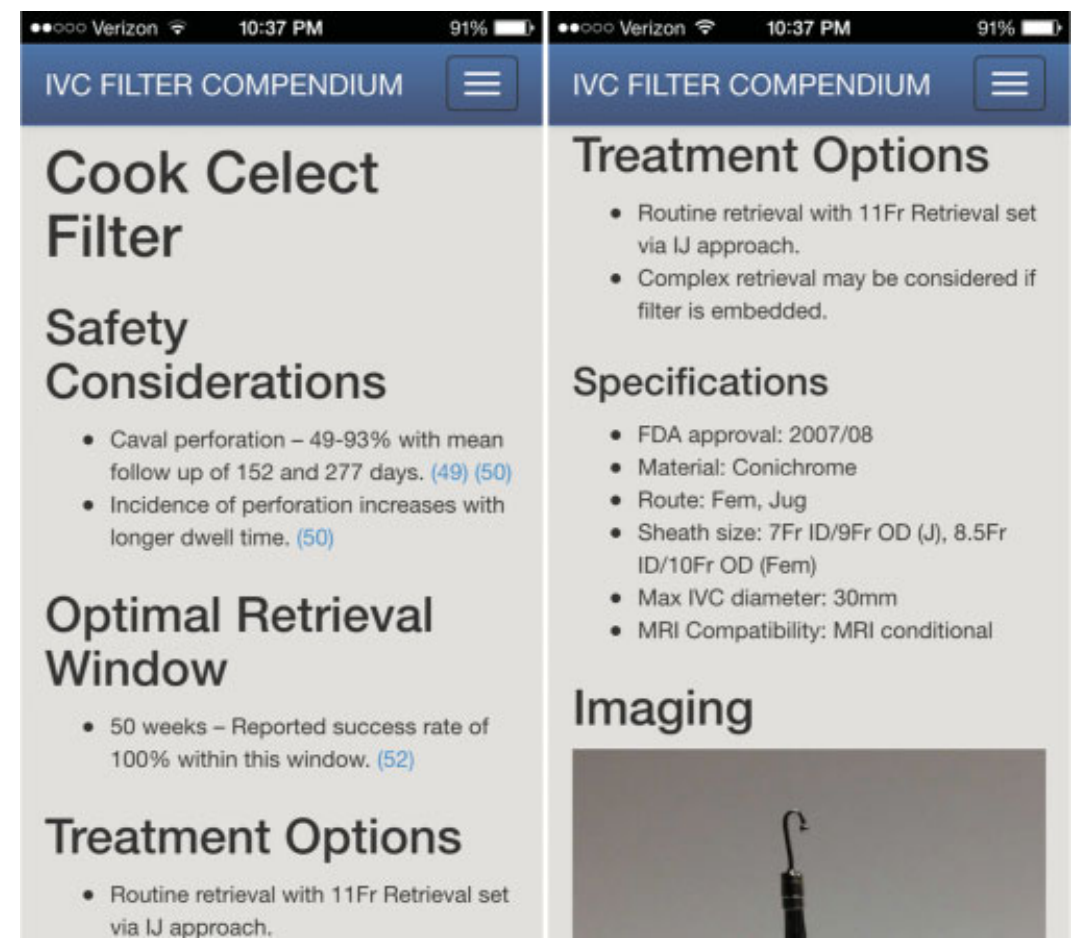

Fig. 7 Screenshots of the information page for the Cook Celect filter. 


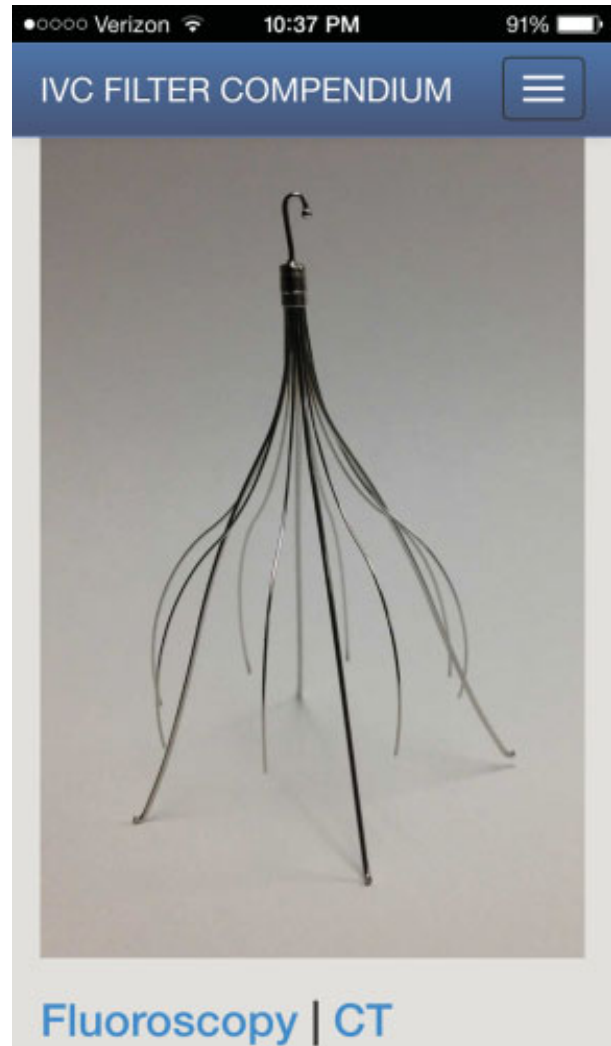

Fig. 8 Screenshot showing the imaging available for each device. A highresolution photograph is immediately available to the user. The fluoroscopic and scrollable CT images are available by hyperlink (below photo).

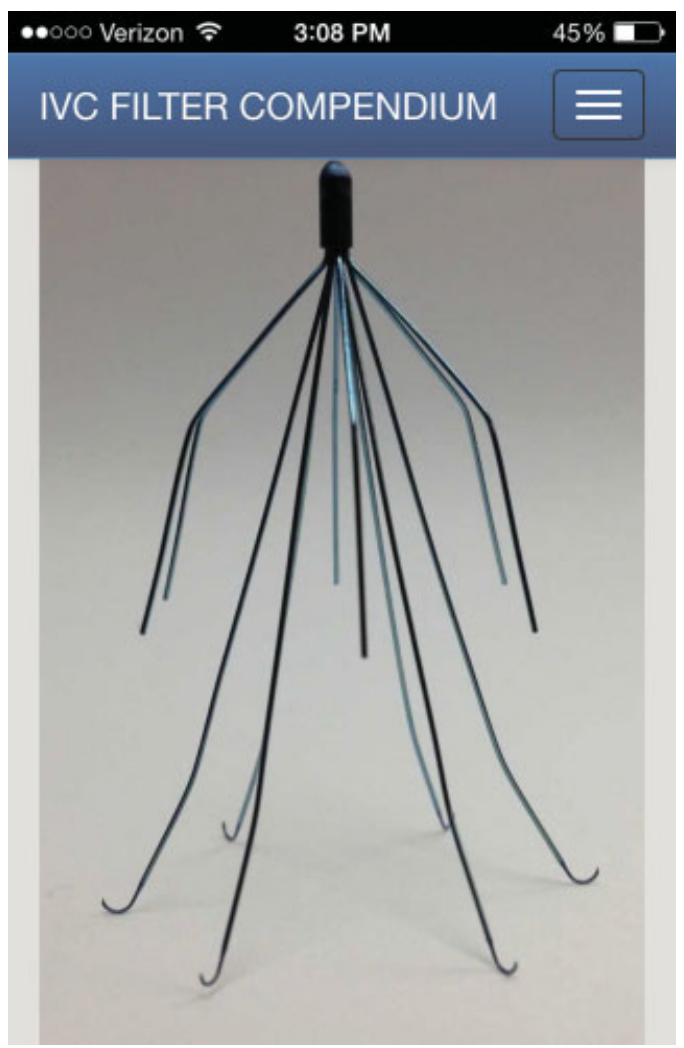

Fig. 10 Screenshot of the image gallery showing the Bard Recovery retrievable IVC filter.

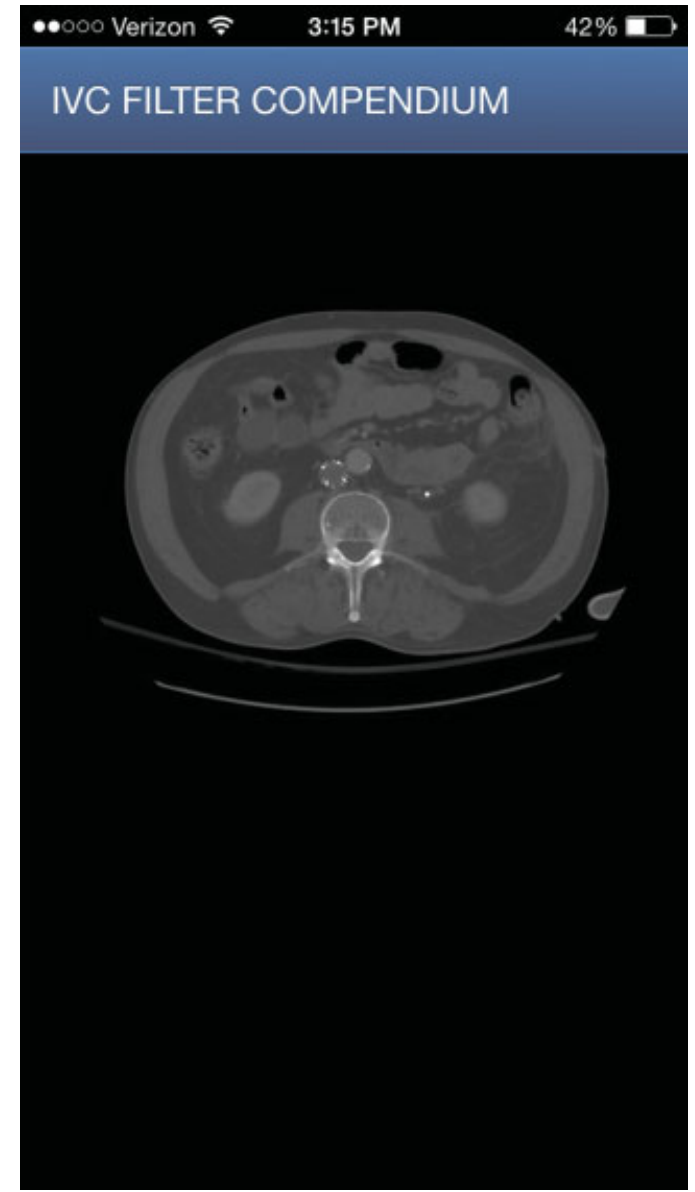

Fig. 9 Screenshot of a scrollable CT showing the Celect filter appearance on cross-sectional imaging.

abdominal pain, the physician can learn that this filter type is associated with penetration rates of up to $93 \%,{ }^{18}$ and should pay close attention to identify filter penetration as a potential etiology for pain.

In summary, a powerful electronic mobile app was successfully created to allow rapid identification of many IVC filter types and to raise awareness of their potential device-specific complications. The application may serve as an educational tool for medical trainees, clinicians, and patients who wish to learn more about IVC filters, as well as a clinical tool to help optimize the care of patients with IVC filters.

Note

This work was presented at the SIR Annual Scientific Meeting 2015, Atlanta, GA.

\section{Acknowledgment}

This project was funded by the Etta Kalin Moskowitz Research Fund, Department of Radiology, Stanford University, Stanford, CA. 


\section{References}

1 Stein PD, Matta F, Hull RD. Increasing use of vena cava filters for prevention of pulmonary embolism. Am J Med 2011;124(7): 655-661

2 Inferior Vena Cava FDA. (IVC) Filters: Initial Communication: Risk of Adverse Events with Long Term Use. Available at: http://www. fda.gov/MedicalDevices/Safety/AlertsandNotices/ucm221676. htm. Published 2010. Accessed January 1, 2015

3 FDA. 510(K) Premarket Notification Database. Available at: http:// www.accessdata.fda.gov/scripts/cdrh/cfdocs/cfpmn/pmn.cfm. Published 2014. Accessed January 1, 2015

4 FDA. MAUDE-Manufacturer and User Facility Device Experience Database. Available at: http://www.accessdata.fda.gov/ scripts/cdrh/cfdocs/cfmaude/search.cfm. Published 2014. Accessed January 1, 2015

5 Bakal CW, Silberzweig JE. Vascular and Interventional Radiology: Principles and Practice. New York, NY: Thieme; 2011

6 Removing Retrievable Inferior Vena Cava Filters FDA Safety Communication. Available at: http://www.fda.gov/MedicalDevices/ Safety/AlertsandNotices/ucm396377.htm. Published 2014. Accessed January 1, 2015

7 Morales JP, Li X, Irony TZ, Ibrahim NG, Moynahan M, Cavanaugh KJ Jr. Decision analysis of retrievable inferior vena cava filters in patients without pulmonary embolism. J Vasc Surg Venous Lymphat Disord 2013;1(4):376-384

8 Kearon C, Akl EA, Comerota AJ, et al; American College of Chest Physicians. Antithrombotic therapy for VTE disease: antithrombotic therapy and prevention of thrombosis: American College of Chest Physicians evidence-based clinical practice guidelines. Chest 2012;141(2, Suppl):e419S-e494S

9 Jaff MR, McMurtry MS, Archer SL, et al; American Heart Association Council on Cardiopulmonary, Critical Care, Perioperative and Resuscitation; American Heart Association Council on Peripheral Vascular Disease; American Heart Association Council on Arteriosclerosis, Thrombosis and Vascular Biology. Management of massive and submassive pulmonary embolism, iliofemoral deep vein thrombosis, and chronic thromboembolic pulmonary hypertension: a scientific statement from the American Heart Association. Circulation 2011;123(16):1788-1830

10 Rogers FB, Cipolle MD, Velmahos G, Rozycki G, Luchette FA. Practice management guidelines for the prevention of venous thromboembolism in trauma patients: the EAST practice management guidelines work group. J Trauma 2002;53(1): 142-164

11 Kaufman JA, Kinney TB, Streiff MB, et al. Guidelines for the use of retrievable and convertible vena cava filters: report from the Society of Interventional Radiology multidisciplinary consensus conference. J Vasc Interv Radiol 2006;17(3):449-459

12 Ventola CL. Mobile devices and apps for health care professionals: uses and benefits. P T 2014;39(5):356-364

13 Divall P, Camosso-Stefinovic J, Baker R. The use of personal digital assistants in clinical decision making by health care professionals: a systematic review. Health Informatics J 2013; 19(1):16-28

14 Nicholson W, Nicholson WJ, Tolerico P, et al. Prevalence of fracture and fragment embolization of Bard retrievable vena cava filters and clinical implications including cardiac perforation and tamponade. Arch Intern Med 2010;170(20):1827-1831

15 Hull JE, Robertson SW. Bard Recovery filter: evaluation and management of vena cava limb perforation, fracture, and migration. J Vasc Interv Radiol 2009;20(1):52-60

16 Vijay K, Hughes JA, Burdette AS, et al. Fractured Bard Recovery, G2, and G2 express inferior vena cava filters: incidence, clinical consequences, and outcomes of removal attempts. J Vasc Interv Radiol 2012;23(2):188-194

17 Kalva SP, Athanasoulis CA, Fan CM, et al. "Recovery" vena cava filter: experience in 96 patients. Cardiovasc Intervent Radiol 2006; 29(4):559-564

18 Durack JC, Westphalen AC, Kekulawela S, et al. Perforation of the IVC: rule rather than exception after longer indwelling times for the Günther Tulip and Celect retrievable filters. Cardiovasc Intervent Radiol 2012;35(2):299-308 